\title{
IRRIGAÇÃO
}

NOTA

\section{INFLUÊNCIA DE DÉFICITS HÍDRICOS CONTROLADOS NA UNIFORMIZAÇÃO DO FLORESCIMENTO E PRODUÇÃO DO CAFEEIRO EM TRÊS DIFERENTES CONDIÇÕES EDAFOCLIMÁTICAS DO ESTADO DE SÃO PAULO ( $\left.{ }^{1}\right)$}

\author{
EMERSON ALVES DA SILVA $\left({ }^{2 *}\right)$; ORIVALDO BRUNINI $\left({ }^{3}\right)$; EMILIO SAKAI $\left({ }^{3}\right)$; \\ FLAVIO BUSSMEYER ARRUDA $\left({ }^{3}\right)$; REGINA CÉLIA DE MATTOS PIRES $\left({ }^{3}\right)$
}

\begin{abstract}
RESUMO
O objetivo foi avaliar a influência de déficits hídricos controlados no florescimento e na produção de cafeeiro Arábica (Coffea arabica L. cv. Obatã enxertados sobre C. canephora cv. Apoatã) em três diferentes condições edafoclimáticas do Estado de São Paulo. As plantas, com idade inicial de 2,5 anos foram cultivadas em espaçamento 2,5 x 1,0 m, no período de julho de 2001 a maio de 2002, nas localidades paulistas de Adamantina, Mococa e Campinas, sob as seguintes condições de manejo de água: não-irrigado (NI), irrigado continuamente (IC) e irrigados com suspensão da irrigação por 30 dias em julho (I30) e 60 dias em julho e agosto (I60). Independentemente da localidade, nos três tratamentos irrigados (IC, I30 e I60) houve maior produção de cafés por planta em relação às plantas não irrigadas (NI), sendo as maiores diferenças signi4ficativas observadas em Mococa. O tratamento I60 favoreceu a obtenção de déficits hídricos da ordem de -1,1 MPa em Adamantina, -1,6 MPa em Mococa e -1,2 MPa em Campinas, os quais foram mais efetivos na sincronização das floradas do cafeeiro aliando uniformidade com alta produção. $\mathrm{O}$ maior número de floradas e a baixa uniformidade de produção das plantas irrigadas continuamente (IC) confirmam a necessidade de um período de seca na sincronização do florescimento. Os baixos valores de potencial da água $\left(\Psi_{\text {wa }}\right)$ nas folhas $(-2,5$ a $-2,8 \mathrm{MPa})$ das plantas não irrigadas (NI) reduziram significativamente o número de flores, se comparadas às plantas irrigadas, com reflexos na produção final, indicando a necessidade de irrigação para assegurar boa iniciação floral.
\end{abstract}

Palavras-chave: Déficit hídrico, irrigação, potencial hídrico, sincronização do florescimento.

$\left(^{1}\right)$ Recebido para publicação em 3 de setembro de 2007 e aceito em 6 de janeiro de 2009.

$\left(^{2}\right)$ Instituto de Botânica, Seção de Fisiologia e Bioquímica de Plantas, Caixa Postal 4005, 01061-970 São Paulo (SP), Brasil. E-mail: easilva@ibot.sp.gov.br $\left(^{*}\right)$ Autor para correspondência.

$\left(^{3}\right)$ Instituto Agronômico de Campinas, Centro de Pesquisa e Desenvolvimento de Ecofisiologia e Biofísica, Caixa Postal 28, 13012-970, Campinas (SP), Brasil. 


\title{
ABSTRACT \\ INFLUENCE OF CONTROLLED WATER DEFICITS ON FLOWERING SYNCHRONIZATION AND YIELD OF COFFEE UNDER THREE DISTINCT EDAPHO-CLIMATIC CONDITIONS OF SÃO PAULO STATE, BRAZIL
}

\begin{abstract}
This work aimed to investigate the influence of controlled water deficits on flowering and yield of Arabica coffee (Coffea arabica L. cv. Obatã grafted on C. canephora cv. Apoatã) in three different local conditions of São Paulo State, in the counties of Adamantina, Mococa and Campinas. Plants, with 2.5 years old, were cultivated at full sun, on spacing $2.5 \mathrm{~m}$ x $1.0 \mathrm{~m}$, from July of 2001 to May of 2002, under the following water management: non irrigated (NI), irrigated continually (IC) and withholding irrigation by 30 days in the month of July (I30) and 60 days the months of July and August (I60). Irrespective of local cultivation, the irrigation provided larger yield of coffee per plant, with the largest significant differences observed in Mococa. The treatment I60 was able to impose a predawn leaf water potential $\left(\Psi_{\text {wa }}\right.$ ) of -1.1 in Adamantina, -1.6 in Mococa and -1.2 in Campinas, which was more effective for flowering synchronization of coffee plants, allying yield uniformity with good production. A greater number of flowers and a low yield uniformity of continually irrigated plants (IC) to ratify the importance of a controlled drought period for flowering synchronization. The low $\mathrm{Y}_{\text {wa }}$ values $(-2.5$ to $-2.8 \mathrm{MPa})$ of the non irrigated plants (NI), reduced the number of flowers per plant when compared to the irrigated plants with reflexes in the final production indicating the need of irrigation in order to assure good floral initiation.
\end{abstract}

Key words: Flower synchronization, irrigation, water deficit, water potential.

\section{Introdução}

Além do próprio comportamento fenológico da cultura, vários fatores do ambiente como, suprimento de água (Dean, 1939; Moens, 1962), temperatura do ar (MEs, 1957; Went, 1957; Wormer e Gituanja, 1970; Drinnan e Menzel, 1995) e níveis de irradiância (CAstillo e Lopes, 1966) influenciam no florescimento, desenvolvimento dos frutos e na produtividade do cafeeiro. No entanto, o fator dominante sobre os ciclos vegetativo e reprodutivo do cafeeiro é bastante variável (Gopal, 1974) e depende, portanto, do local de cultivo e de práticas de manejo, dentre as quais se destaca a irrigação.

De fato, a literatura sobre a influência dos fatores ambientes no florescimento do cafeeiro é bastante controversa (Drinnan e Menzel, 1995). Segundo CAMARGo et al. (1977), quando cultivado em áreas climaticamente aptas, com condições térmicas e hídricas favoráveis, pode-se admitir o fotoperíodo como fator condicionante da época de florescimento do cafeeiro Arábica. Por outro lado, CAnnel (1972) sugere que variações sazonais no crescimento e desenvolvimento floral de cafeeiros seriam reguladas por outros fatores que não o fotoperíodo, uma vez que tanto plantas jovens quanto adultas de várias cultivares de Coffea arabica foram fotoperiodicamente insensíveis, mantendo sua capacidade de floração independente do comprimento do dia, sendo mais provável que as respostas das plantas fossem condicionadas por flutuações na temperatura do ar e no suprimento de água.
No aspecto hídrico, a irrigação na cafeicultura tem se justificado pela possibilidade de expansão da cultura em áreas antes limitadas pela deficiência hídrica ou distribuição irregular das chuvas, e nas regiões tradicionais por oferecer a garantia de produção em anos de baixa precipitação pluvial ou quando ocorrem veranicos nas fases críticas de desenvolvimento dos frutos (SAKAI 2000). No entanto, as necessidades de irrigação e sua função no controle da época de florescimento, são muito variáveis e dependentes da distribuição das chuvas, severidade da estação seca e do tipo e profundidade dos solos.

Com efeito, a sincronização do florescimento em cafeeiros tem sido associada com ciclos de déficits internos de água nas plantas, os quais quebrariam a dormência das gemas florais totalmente diferenciadas, levando ao florescimento após a aplicação da água por irrigação ou chuva. Conforme trabalhos realizados no Havaí, tais déficits podem variar de $-0,8 \mathrm{MPa}$ (CRISOsto et al., 1992) a -2,65 MPa (SCHUCH et al., 1992). No Brasil, MagalHães e AngelocCi (1976) observaram que um limiar de potencial da água nas folhas do cafeeiro de -1,2 MPa deveria ser estabelecido para promover o processo de floração em resposta à irrigação.

Entretanto, a maioria desses trabalhos foi realizada sob ambientes controlados e, mesmo que sob condições de campo, objetivou somente estabelecer uma relação entre a intensidade do déficit hídrico imposto à planta e a uniformização das floradas. Assim, não determinam um intervalo de tempo necessário para se estabelecer um déficit hídrico que 
fosse suficiente para quebrar a dormência das gemas florais e estimular a sincronização do florescimento e desenvolvimento dos frutos, bem como, não quantificam os reflexos na produção final dos cafeeiros. Tais informações podem viabilizar o desenvolvimento de práticas que auxiliem o agricultor a planejar e utilizar a água de irrigação eficientemente para o aumento da produção e qualidade do café (GUERRA et al. 2007).

Dessa maneira, experimentos adicionais são requeridos para prover melhor interação entre déficit hídrico, irrigação e florescimento com o intuito de obter práticas de cultivo que consolidem o período de colheita.

Assim, o presente trabalho objetivou avaliar a influência de déficits hídricos controlados na uniformização do florescimento e da produção do cafeeiro arábica sob distintas condições edafoclimáticas do Estado de São Paulo, Brasil.

\section{Material e Métodos}

Material vegetal e condições de cultivo - Os experimentos foram desenvolvidos no período de julho de 2001 a maio de 2002, utilizando-se plantas de Coffea arabica L. cv. Obatã IAC 1669-20, enxertadas sobre C. canephora cv. Apoatã e com idade inicial de 2,5 anos. As plantas foram cultivadas sob condições de campo em espaçamento $2,5 \times 1,0 \mathrm{~m}$, em três áreas experimentais situadas nas localidades de Adamantina $\left(21^{\circ} 41^{\prime} \mathrm{S}, 51^{\circ} 05^{\prime} \mathrm{O}\right.$ e altitude de $\left.443 \mathrm{~m}\right)$, Mococa $\left(21^{\circ} 28^{\prime} \mathrm{S}, 47^{\circ} 01^{\prime} \mathrm{O}\right.$ e altitude de $\left.663 \mathrm{~m}\right)$ e Campinas $\left(22^{\circ} 54^{\prime} \mathrm{S}, 47^{\circ} 05^{\prime} \mathrm{O}\right.$ e altitude de $\left.669 \mathrm{~m}\right)$.

Em Adamantina (AD) e Mococa (MC), os experimentos foram instalados nos Pólos Regionais de Desenvolvimento Tecnológico dos Agronegócios da Alta Paulista e do Nordeste Paulista respectivamente, e em Campinas (CP), no Centro Experimental Central, do Instituto Agronômico (IAC). Os solos das três áreas foram classificados (EMBRAPA, 1999), respectivamente, como Latossolo Vermelho Eutrófico de textura média (Prado et al., 2003), Argissolo Vermelho Eutrófico textura média e Latossolo Vermelho Eutrófico textura muito argilosa respectivamente. O clima das três regiões segundo a classificação de Köppen é do tipo Cwa, tropical de altitude com inverno seco e verão úmido e quente (RUSso JúNIOR, 1980).

Em cada localidade, os cafeeiros foram submetidos aos seguintes tratamentos: não-irrigados (NI), irrigados continuamente (IC) e irrigados com suspensão da irrigação por 30 dias em julho (I30) e 60 dias em julho e agosto (I60). Em cada tratamento, foram sorteadas 10 plantas ao acaso, as quais foram utilizadas para as análises ao longo do estudo.
Foi instalado o sistema de irrigação do tipo localizado por gotejamento na superfície. A lâmina de irrigação foi igual a $4 \mathrm{~mm}$ diários, determinada de acordo com a evapotranspiração média de cada localidade, aplicados diariamente. Os tratos culturais, tais como capina, adubação e aplicação de defensivos foram realizados seguindo as recomendações do Boletim 200 (FAzUOLI et al., 1998), do Instituto Agronômico (IAC).

Temperatura do ar e precipitação pluvial Para acompanhar e caracterizar as variações climáticas de cada localidade ao longo do período experimental, foram obtidos diariamente dados da temperatura do ar e precipitação pluvial de Estações Meteorológicas Automáticas (EMAs) situadas a aproximadamente $500 \mathrm{~m}$ das áreas experimentais.

Os dados foram agrupados em intervalos quinzenais para cálculo da temperatura média e intervalos mensais para o somatório de precipitação pluviométrica.

Potencial da água na folha na antemanhã $\left(\Psi_{\text {wa }}\right)$ - O potencial da água nas folhas dos cafeeiros foi determinado entre $4 \mathrm{~h}$ e $5 \mathrm{~h}$ utilizando-se uma bomba de pressão tipo Scholander (SCHOLANDER et al., 1965) da PMS Instrument (modelo 1000 Corvallis, EUA). Para as medidas foram utilizadas somente folhas totalmente expandidas e não danificadas, do terceiro ou quarto par a partir do ápice de ramos plagiotrópicos do terço médio superior das plantas. As leituras foram realizadas tão logo as folhas eram destacadas das plantas. Consideraram-se 10 repetições por tratamento, sendo uma única folha utilizada para determinar o $\Psi_{\text {wa }}$ de uma planta. As medidas foram realizadas em intervalos quinzenais no período de julho a setembro, e mensais nos demais meses do ano.

Florescimento e uniformidade de produção A intensidade do florescimento foi quantificada pela contagem no número de frutos "chumbinho", estádio 7 conforme a classificação de CRIsOsto e Grantz (1990), resultantes de cada florada. Para tanto, foram marcados três ramos plagiotrópicos primários do terço médio superior em cada uma das 10 plantas de cada tratamento, totalizando 30 repetições. A contagem foi realizada até 30 dias após o encerramento do processo de floração, obtendo-se no fim o número total de chumbinhos surgidos por ramo até a última florada.

A uniformidade de produção com relação ao estádio de maturação dos frutos foi, por sua vez, determinada pela relação entre número de frutos verdes ou cerejas presentes naqueles ramos na época da colheita e o total de frutos colhidos por ramo expressa em porcentagem. 
Produção por planta, rendimento e peneira média - Para a obtenção desses dados, a produção final de cada uma das 10 plantas utilizadas durante os experimentos, foi colhida sob a forma de derriça em peneira, para evitar queda dos frutos no chão. $\mathrm{O}$ processamento do café recém-colhido foi realizado pelo método da via seca em terreiro. Para tal, a produção de café cereja de cada planta foi acondicionada separadamente em sacos de tela de náilon, os quais foram colocados para secar ao sol, com constante revolvimento durante o dia. Após a secagem que levou aproximadamente 15 dias, procedeu-se o beneficiamento dos frutos para remoção da casca e do pergaminho.

A produção nos diferentes tratamentos foi expressa em $\mathrm{kg}$ planta $^{-1}$ de café beneficiado. $\mathrm{O}$ rendimento no benefício, em porcentagem, foi calculado pela relação entre a massa de café beneficiado e o de café em coco.

Os valores de peneira média foram, por sua vez, determinados de acordo com KRUG (1940) em 10 amostras de 100 gramas de café beneficiado por tratamento, obtidas da produção de cada uma das plantas.

Análise estatística - Os dados referentes aos parâmetros de produção foram submetidos a análises de variância, sendo o teste de significância de Duncan utilizado para a comparação das médias, a 5\% de probabilidade. Foram comparadas as médias dos diferentes tratamentos de uma mesma localidade. Utilizou-se a estatística descritiva para os demais dados.

\section{Resultados e Discussão}

Variação sazonal nos parâmetros climáticos: A figura 1 mostra respectivamente as variações da temperatura média do ar (Figura 1A) e precipitação pluvial (Figura 1B), no período de junho de 2001 a maio de 2002, nas localidades de Adamantina, Mococa e Campinas. A temperatura média do ar nas respectivas localidades foi de $24,7,22,9$ e $22,5{ }^{\circ} \mathrm{C}$. Como pode ser observado em Adamantina, a temperatura média do ar no período foi cerca de 1,8 a $2,2{ }^{\circ} \mathrm{C}$ mais altas que nas localidades de Mococa e Campinas respectivamente. Tais diferenças foram mais influenciadas pelas variações da temperatura entre setembro e abril, período que compreende a época úmida e quente, sendo até $2,8^{\circ} \mathrm{C}$ mais altas em março e abril de 2002.

A precipitação pluvial por seu turno foi menor em Adamantina em relação a Mococa e Campinas (Figura 1B). As chuvas nessas localidades totalizaram 1128,1607 e $1273 \mathrm{~mm}$ respectivamente, e desses totais, $78,1 \%, 95,8 \%$ e $86 \%$ ocorreram entre setembro de 2001 e março de 2002. No entanto, apesar de menores, as chuvas em Adamantina parecem ter sido mais bem distribuídas ao longo do ano, visto que entre julho e agosto, correspondeu ao período de imposição do déficit pela suspensão da irrigação, o somatório da precipitação pluviométrica foi de $61,2 \mathrm{~mm}$, ao passo que em Campinas e Mococa esses valores foram de 19,7 e $38,9 \mathrm{~mm}$ respectivamente.

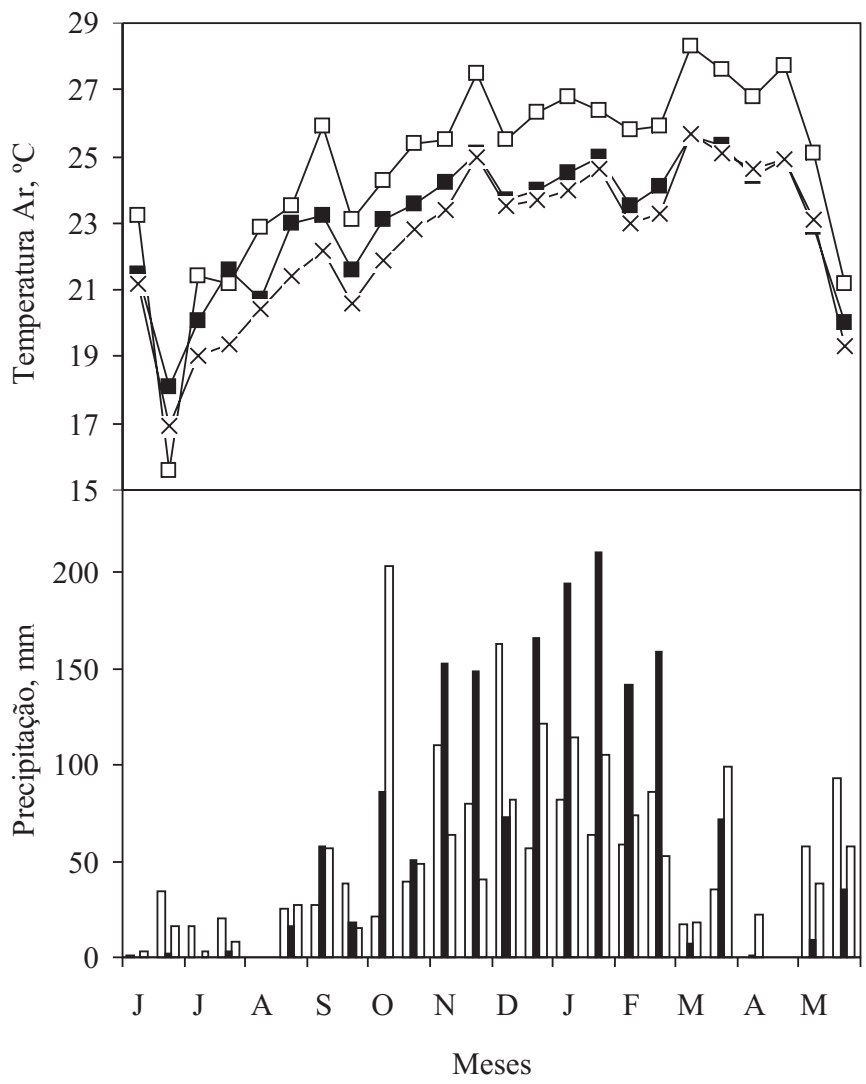

Figura 1. Temperatura do ar $\left({ }^{\circ} \mathrm{C}\right)$ e precipitação $(\mathrm{mm})$ no período de junho de 2001 a maio 2002 nas localidades de Adamantina ( $\square$ ), Mococa ( $\square$ ) e Campinas (X), Estado de São Paulo, Brasil.

Potencial da água nas folha na antemanhã ( $\left.\Psi_{\text {wa }}\right)$ em resposta ao manejo de irrigação e influência no florescimento e nos parâmetros de produção - Os resultados de $\Psi_{\text {wa }}$ das plantas de café nos tratamentos NI, IC, I30 e I60, nas localidades de Adamantina, Mococa e Campinas, são apresentados na figura 2. As chuvas da ordem de $61 \mathrm{~mm}$ ocorridas entre julho e agosto de 2001, em Adamantina, foram responsáveis pela menor diferença entre os tratamentos naquele período. Assim, após a imposição dos tratamentos I30 e I60 a partir de julho, pode-se observar que os menores $\Psi_{\text {wa }}$ foram de $-1,0,-0,50,-1,0$ e $-1,10 \mathrm{MPa}$ nos tratamentos NI, IC, I30 e I60 respectivamente (Figura 2 AD) e que estes foram alcançados aos 30 
dias após a suspensão da irrigação. Adicionalmente, os menores $\Psi_{\text {wa }}$ observados no tratamento NI em abril de 2001, da ordem de $-1,60$ $\mathrm{MPa}$, coincidiram com a falta de chuvas e as altas temperaturas do ar ocorridas naquele mês.

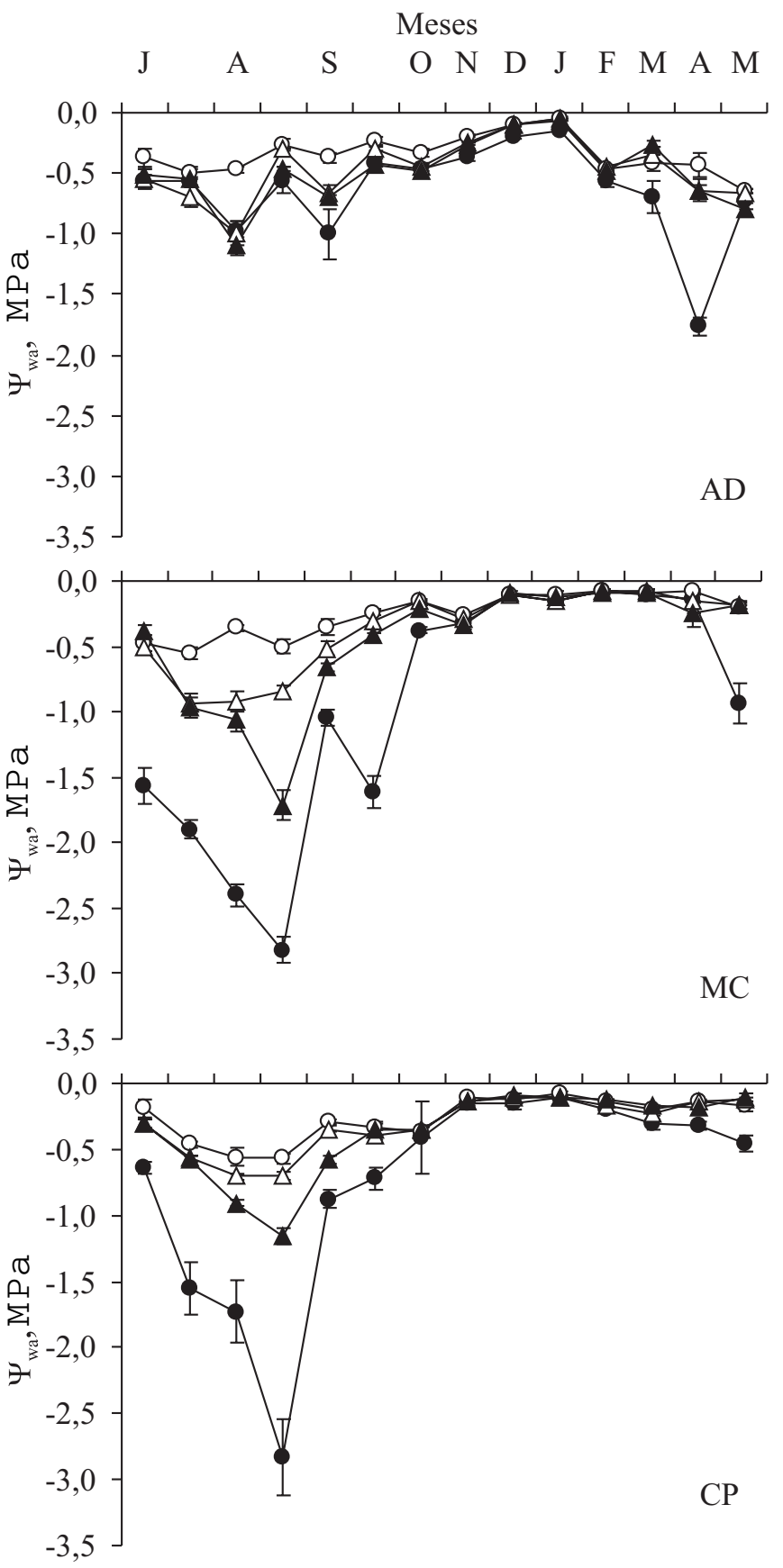

Figura 2. Potencial da água na antemanhã nas folhas $\left(\Psi_{\text {wa }}\right)$ dos cafeeiros nos tratamentos não irrigado ( $)$, irrigados continuamente $(O)$ e irrigados com suspensão da irrigação por 30 dias no mês de julho $(\triangle)$ e 60 dias nos meses de julho e agosto $(\boldsymbol{A})$, nas localidades de Adamantina (AD), Mococa (MC) e Campinas (CP), Estado de São Paulo. Barras indicam o desvio-padrão da média.
Já em Mococa (Figura $2 \mathrm{MC}$ ) e Campinas (Figura $2 \mathrm{CP}$ ), a escassez de chuvas durante a imposição do déficit hídrico favoreceu as marcantes diferenças entre os tratamentos, principalmente no período de julho a agosto de 2001. Como se pode observar, a suspensão da irrigação por 30 e 60 dias correspondeu a $\Psi_{\text {wa }}$ de $-0,90$ e $-1,70 \mathrm{MPa}$ em Mococa e -0,70 e -1,20 MPa em Campinas respectivamente; no tratamento I60, esses potenciais foram alcançados aos 45 dias após a interrupção da irrigação. Sob irrigação contínua, os $\Psi_{\text {wa }}$ mínimos foram de -0,50 MPa. Em condições não irrigadas, tanto em Mococa como em Campinas, ocorreram déficits hídricos da ordem de 2,80 MPa.

Com o objetivo de determinar a intensidade do déficit hídrico necessário para estimular o florescimento do cafeeiro após a irrigação, há na literatura disponível valores limiares de $\Psi_{\text {wa }}$ que variam de $-0,80$ (CRIsosto et al., 1992) até $-2,65 \mathrm{MPa}$ (Schuch et al., 1992). Pelos dados obtidos neste estudo, no entanto, observa-se que os $\Psi_{\text {wa }}$ alcançados nos tratamentos I60, foram de -1,10 MPa em Adamantina, -1,2 em Campinas e -1,7MPa em Mococa, próximos daqueles descritos por MagalHães e AngelocCi (1976). Estes autores, também no Estado de São Paulo, observaram um limiar de $-1,20$ a $-1,40 \mathrm{MPa}$, para que o florescimento da cultivar Mundo Novo fosse estimulado pela irrigação.

Com efeito, o florescimento (Figura 3) foi mais acelerado nas plantas cultivadas sob os tratamentos NI e I60, após o retorno das chuvas e da irrigação. Como pode se observar, em Mococa (Figura $3 \mathrm{MC}$ ), o florescimento nesses tratamentos ocorreu apenas em dois episódios, e 60\% (NI) e 73\% (I60) do número total de chumbinhos surgiram na $1 .^{\text {a }}$ florada ocorrida no início de setembro. De modo semelhante, em Campinas (Figura $3 \mathrm{CP}$ ), do total de chumbinhos observados $100 \%$ e $90 \%$ surgiram após duas floradas nos tratamentos NI e I60 respectivamente.

O menor número de chumbinhos nos tratamentos NI em Mococa e Campinas podem estar associados aos efeitos prejudiciais dos baixos $\Psi_{\text {wa }}$ da ordem de $-2,80 \mathrm{MPa}$ aos quais as plantas ficaram sujeitas (Figuras $3 \mathrm{MC}$ e CP). Esses dados corroboram os observados por Drinnan e Menzel (1994) em que $\Psi_{\text {wa }}$ de $-2,5$ MPa reduziram significativamente o número de inflorescências, se comparado com plantas irrigadas.

De qualquer modo, independentemente da localidade e do tratamento, o florescimento ocorreu no início de setembro. Porém, este foi menos uniforme nos tratamentos IC, nos quais houve, em média, quatro floradas que se estenderam até fins de novembro (Figura 3). 


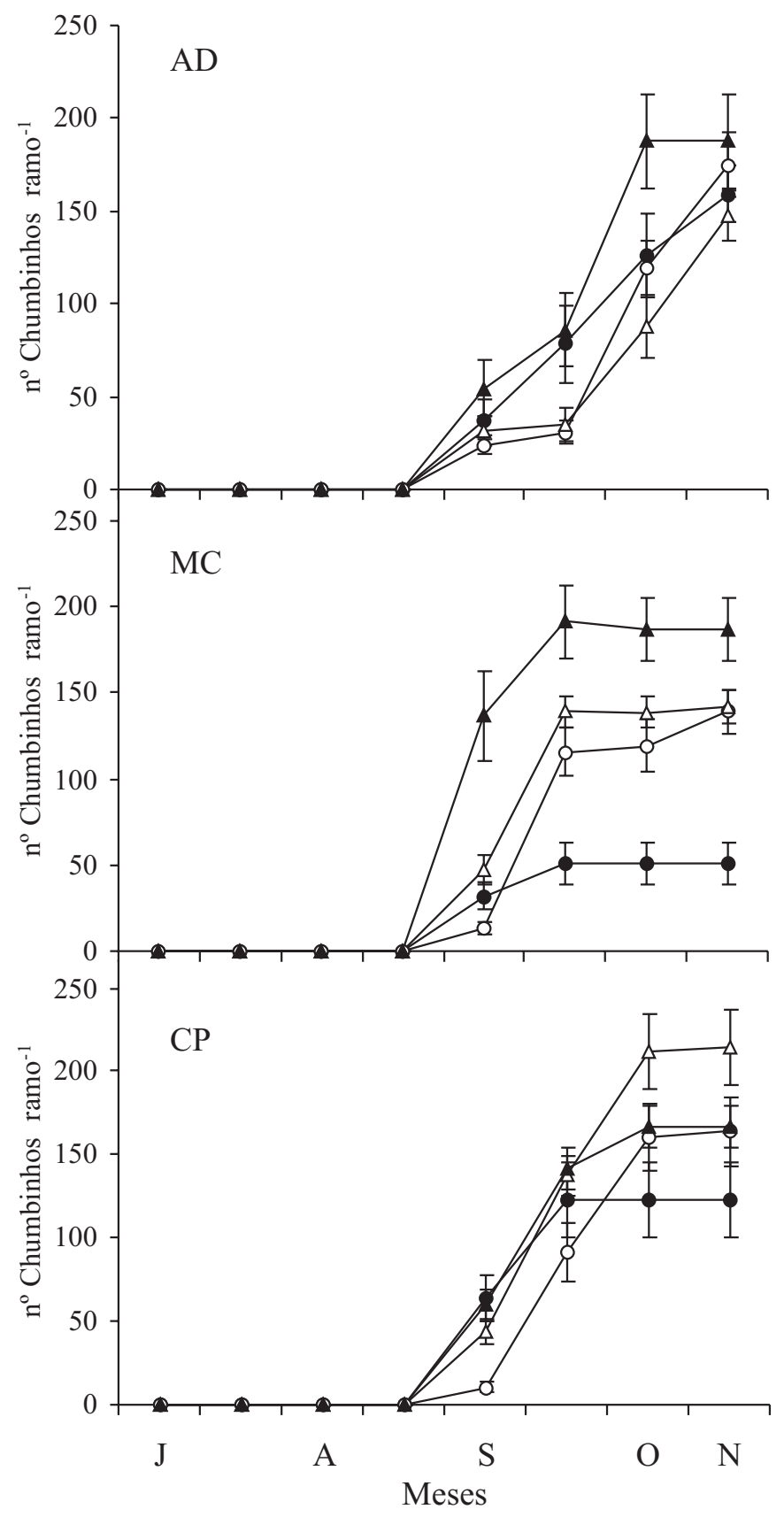

Figura 3. Número de frutos no estádio de chumbinho surgidos após cada florada, nos tratamentos não irrigado $(\bullet)$, irrigados continuamente $(O)$ e irrigados com suspensão da irrigação por 30 dias no mês de julho $(\triangle)$ e 60 dias em julho e agosto $(\boldsymbol{\Delta})$, nas localidades de Adamantina (AD), Mococa (MC) e Campinas (CP), Estado de São Paulo. Barras indicam o desvio-padrão da média.

De fato, na ausência de um período de seca definido, os ciclos de floração são mais frequentes como ocorre nas áreas mais úmidas das regiões produtoras de café (RenA et al., 2001). Segundo Wormer (1965), no Kenya, cafeeiros irrigados no campo durante a estação seca não alteraram seus ritmos de florescimento, se comparados com plantas não irrigadas e com déficit hídrico. Com efeito, plantas de café cultivadas em casa de vegetação, tanto em condições de solo constantemente úmido como em hidroponia, também floresceram na mesma época dos cafeeiros cultivados no campo (Franco, 1970). Esse autor, assim como BrownING e FISHER (1975) sugeriram que mesmo quando irrigadas as plantas de café desenvolveriam um déficit hídrico interno suficiente para quebrar a dormência das gemas. E, segundo BROWNING e Fisher (1975), esse déficit hídrico seria devido à alta resistência desenvolvida pelas raízes ao fluxo de água para a planta, fato confirmado por BRUNINI e ANGELOCCI (1998), quando observaram que a maior resistência ao transporte de água no sistema solo-planta para cultura do cafeeiro está localizada nas raízes. No entanto, nossos dados diferem daqueles obtidos por Alvim (1960), no Peru, e CRisosto et al. (1992), no Havaí, ao observarem em condições de campo e de casa de vegetação, que sob irrigação contínua as gemas florais permaneciam dormentes e o florescimento não ocorria.

Nossos dados permitem observar muito bem que, sob condições de campo, a imposição de déficits hídricos controlados pelo manejo da irrigação no controle do florescimento é bastante dependente da distribuição das chuvas, que podem influenciar na severidade da estação seca (CARR, 2001).

De qualquer forma, no florescimento em diferentes tratamentos constatou-se estreita relação com a uniformidade de desenvolvimento dos frutos, com considerável efeito da irrigação na produção final dos cafeeiros. Pelos dados da tabela 1, pode-se observar que do total de frutos colhidos por ramo, a maior porcentagem de frutos verdes ocorreu nos tratamentos IC para as regiões de Mococa e Campinas e I30 para a região de Adamantina. De modo oposto, a maior porcentagem de frutos cereja foi observada nos tratamentos NI e I60, para a região de Adamantina e Mococa e I30 e I60 para a região de Campinas, e em I60, a boa uniformidade esteve aliada à maior produção por planta.

De fato, os maiores valores de produção por planta em cada localidade foram obtidos nos tratamentos irrigados, com diferenças significativas em relação aos tratamentos NI para as regiões de Adamantina e Mococa, sendo a maior delas obtida em Mococa (Tabela 1) com 0,10, 1,09, 1,08 e 1,09 kg planta $^{-1}$ de café beneficiado, nos tratamentos NI, IC, I30 e I60 respectivamente. Considerando-se o espaçamento em que as plantas foram cultivadas $(2,5 \mathrm{~m} \times 1,0 \mathrm{~m})$, isso corresponde a uma produtividade de 400,4360, 4320 e $4360 \mathrm{~kg} \mathrm{ha}^{-1}$. Dados semelhantes foram obtidos por SAKAI et al. 
(2003) em um experimento que avaliou o efeito de diferentes intervalos de irrigação na produtividade da cultivar Obatã em Mococa, com valores médios de $662 \mathrm{~kg} \mathrm{ha}^{-1}$ no tratamento não irrigado e 4400 $\mathrm{kg} \mathrm{ha}{ }^{-1}$ nos cafeeiros irrigados. Esses autores também avaliaram o rendimento no benefício e a peneira média dos grãos de café, e observaram que a renda variou de $43 \%$ a $48 \%$ e a peneira média entre 16 e 17.

Nossos dados foram semelhantes, constatando-se que o rendimento no processamento e o tamanho do grão indicado pela peneira média variaram de 42,5 a $49 \%$ e de 16 a 18 respectivamente, independentemente dos tratamentos e da localidade (Tabela 1). Ainda na tabela 1 , nota-se não haver diferenças significativas no rendimento nas regiões de Adamantina e Mococa, para qualquer tratamento e que houve uma pequena variação de $45,3 \%$ a $50,3 \%$ na região de Campinas. Para Adamantina e Mococa, a variação foi de $42,5 \%$ a $47,4 \%$ e de $46,2 \%$ a $46,8 \%$ respectivamente. Em uma caracterização de cultivares e linhagens de café tipo Arábica, Aguiar (2001) determinou para a cultivar Obatã em Mococa, sob condições de sequeiro, rendimento de $43 \%$ e peneira média de 16,8. Assim, no que se refere ao rendimento, todos os casos apresentados, ficaram abaixo de 50\%, que é considerado por MôNACO (1960) um valor ideal. Já a alta peneira média observada no tratamento NI em Mococa pode ser conseqüência da baixíssima produção, o que permitiria maior investimento de matéria seca por fruto produzido. No aspecto geral, a irrigação não propiciou maiores rendas ou peneiras, em detrimento, talvez, das maiores produções em relação aos tratamentos não irrigados.

Outro aspecto a destacar é que a produção final foi definida logo no florescimento, pois a porcentagem de perda avaliada pelo número de frutos colhidos por ramo em relação ao total de chumbinhos produzidos após as floradas, foi semelhante nos tratamentos impostos. Além disso, as maiores perdas ocorreram inclusive em tratamentos irrigados, como pode ser observado nos tratamentos I60 em Mococa e I30 em Adamantina (Tabela 1), com valores de 31,4\% e $34,7 \%$ de perdas. Segundo CARR (2001), tais reduções podem ser devidas a fatores como a polinização ou a fertilização inadequada, períodos prolongados de seca antes, durante e $\log$ o após o florescimento e até a competição por espaço devido ao excesso de frutos por nó. Em todo caso, independente da carga dos cafeeiros o pegamento dos frutos ficou acima de $50 \%$, diferente do afirmado por ReIs e ARRUda (1956) que no Brasil o pegamento de frutos do cafeeiro Arábica é em média de $40 \%$. Entretanto, a maior produção nos tratamentos irrigados, reforça a importância dessa prática em períodos críticos como a iniciação floral conforme já fora sugerido por DRINNAN e MENZEL (1994).

Tabela 1. Parâmetros de produção dos cafeeiros cultivados nos tratamentos não irrigado (NI), irrigados continuamente (IC) e irrigados com suspensão da irrigação por 30 dias no mês de julho (I30) e 60 dias em julho e agosto (I60), no período de julho de 2001 a maio de 2002, nas localidades de Adamantina (AD), Mococa (MC) e Campinas (CP), Estado de São Paulo

\begin{tabular}{|c|c|c|c|c|c|c|c|c|}
\hline \multirow{3}{*}{ Local } & \multicolumn{8}{|c|}{ Parâmetros de Produção } \\
\hline & \multirow{2}{*}{ Tratamentos } & \multirow{2}{*}{ Chumbinhos } & \multicolumn{3}{|c|}{ Frutos } & \multirow{2}{*}{ Produção } & \multirow{2}{*}{ Renda } & \multirow{2}{*}{$\begin{array}{c}\text { Peneira } \\
\text { Média }\end{array}$} \\
\hline & & & Colhidos & Verdes & Cereja & & & \\
\hline & & ${ }^{1}$ & $\bar{u}$ & 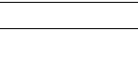 & 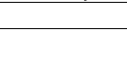 & kg planta ${ }^{-1}$ & $\%$ & \\
\hline \multirow[t]{4}{*}{$\mathrm{AD}$} & $\mathrm{NI}$ & $159 \mathrm{~ns}$ & $114 a b$ & 4,4 & 95,6 & $0,68 \mathrm{a}$ & $45,2 \mathrm{~ns}$ & $16,0 \mathrm{a}$ \\
\hline & IC & $177 \mathrm{~ns}$ & $130 \mathrm{ab}$ & 18,4 & 81,6 & $0,86 \mathrm{ab}$ & 42,3 ns & $16,5 \mathrm{ab}$ \\
\hline & $\mathrm{I} 30$ & $147 \mathrm{~ns}$ & $96 a$ & 26,0 & 74 & $0,89 b$ & $42,5 \mathrm{~ns}$ & $16,8 \mathrm{bc}$ \\
\hline & $\mathrm{I} 60$ & $188 \mathrm{~ns}$ & $164 b$ & 3,2 & 96,8 & $0,95 b$ & $47,4 \mathrm{~ns}$ & $17,2 \mathrm{c}$ \\
\hline \multirow[t]{4}{*}{$\mathrm{MC}$} & NI & $51 a$ & $36 a$ & 5,2 & 94,8 & $0,10 \mathrm{a}$ & $46,0 \mathrm{~ns}$ & $18,0 \mathrm{~b}$ \\
\hline & $\mathrm{IC}$ & $142 b$ & $114 b$ & 48,7 & 51,3 & $1,09 b$ & $46,2 \mathrm{~ns}$ & $16,8 \mathrm{a}$ \\
\hline & I30 & $142 b$ & $124 \mathrm{~b}$ & 21,7 & 78,3 & $1,08 b$ & $46,8 \mathrm{~ns}$ & $16,9 a$ \\
\hline & I60 & 191c & $131 b$ & 11 & 89 & $1,09 b$ & $46,5 \mathrm{~ns}$ & $17,0 \mathrm{a}$ \\
\hline \multirow[t]{4}{*}{$\mathrm{CP}$} & NI & $122 a$ & $99 a$ & 11,1 & 88,9 & $0,52 \mathrm{a}$ & $45,3 a$ & $16,9 \mathrm{~ns}$ \\
\hline & IC & $161 \mathrm{ab}$ & $156 a b$ & 39,4 & 60,6 & $0,63 a$ & $50,3 c$ & $17,1 \mathrm{~ns}$ \\
\hline & $\mathrm{I} 30$ & $212 b$ & $195 b$ & 8,3 & 91,7 & $1,07 \mathrm{~b}$ & $46,1 \mathrm{ab}$ & $16,7 \mathrm{~ns}$ \\
\hline & $\mathrm{I} 60$ & $167 \mathrm{ab}$ & $141 \mathrm{ab}$ & 5,8 & 94,2 & $1,29 c$ & $47,9 b$ & $16,7 \mathrm{~ns}$ \\
\hline
\end{tabular}

Médias seguidas de letras distintas diferem estatisticamente entre si pelo teste de Duncan em nível de 5\% de probabilidade. ns = não significativo. 
Pelos dados obtidos nesse trabalho, permitese concluir que, sob condições de campo, a irrigação proporcionou maior produção $\left(\mathrm{kg}\right.$ planta $\left.{ }^{-1}\right)$ de café por planta, independentemente da localidade, sendo as maiores diferenças significativas observadas em Mococa. Com relação ao florescimento, a suspensão da irrigação por 60 dias em julho e agosto, favoreceu a obtenção de déficits hídricos $(-1,1$ a $-1,6 \mathrm{MPa})$ que foram mais efetivos na sincronização das floradas do cafeeiro Obatã, aliando uniformidade com alta produção. A menor diferença entre os tratamentos em Adamantina demonstrou que esse manejo é dependente das condições edafoclimáticas preponderantes. O maior número de floradas e a baixa uniformidade de produção das plantas irrigadas continuamente confirmam a necessidade de um período de seca na sincronização do florescimento. Os baixos valores $\mathrm{de}_{\mathrm{wa}}(-2,5 \mathrm{a}-2,8 \mathrm{MPa})$ das plantas não irrigadas reduziram significativamente o número de flores se comparadas às plantas irrigadas, com reflexos na produção final, indicando a necessidade de irrigação para assegurar boa iniciação floral.

\section{Agradecimentos}

Os autores agradecem ao Consórcio Brasileiro de Pesquisa e Desenvolvimento do Café (CBP\&DCafé/Embrapa) pelo financiamento deste trabalho. E.A. Silva e O. Brunini agradecem ao Conselho Nacional de Desenvolvimento Científico e Tecnológico (CNPq) pela concessão das Bolsas de Doutorado e Produtividade em Pesquisa respectivamente.

\section{Referências}

AGUIAR, A.T.E. 2001. Descritores para caracterização de cultivares e linhagens de café tipo Arábica. 2001. $98 \mathrm{fl}$. Dissertação (Mestrado). Instituto Agronômico, Campinas.

ALVIM, P.T. Moisture stress as a requirement for flowering of coffee. Science, Washington DC, v. 132, p. 354, 1960.

BROWNING, G.; FISHER, N.M. Shoot growth in Coffea arabica L. II. Growth flushing stimulated by irrigation. Journal of Horticultural Science, London, v. 50, p. 207-218, 1975.

BRUNINI, O.; ANGELOCCI, L.R. Resistência ao fluxo de água no sistema solo-planta e recuperação do potencial da água na folha após estresse hídrico em mudas de cafeeiro. Revista Brasileira de Fisiologia Vegetal, Campinas, v. 10, p. 45-50, 1998.

CAMARGO, A.P., ALFONSI, R.R., PINTO, H.S., CHIARINI, J.V. Zoneamento da aptidão climática para culturas comerciais em áreas de cerrado. In: M.FERRI (Coord.). SIMPÓSIO SOBRE CERRADO, 4., 1977, Brasília. Anais... São Paulo: Edusp, 1977. p. $89-120$.
CANNEL, M.G.R. Photoperiodic response of mature trees of Arabica coffee. Turrialba, San Jose, v. 22, p.198-206, 1972.

CARR, M.K.V. The water relations and irrigation requeriments of coffee. Experimental. Agriculture, Cambridge, v. 37, p. 1-36, 2001.

CASTILLO-Z., J.; LOPEZ-A., R. Nota sobre el efecto de la intensidad de la luz en la floracion del cafeto. Cenicafé, Chinchiná, v. 17, p. 51-60, 1966.

CRISOSTO, C.H.; GRANTZ, D.A. Response of coffee (Coffea arabica L.) bud developmental stage to water status. In: INTERNATIONAL HORTICULTURAL CONGRESS, 23., 1990, Florenze. Abstracts... Florenze, 1990. v.1. p.277.

CRISOSTO, C.H., GRANTZ, D.A., MEIZER, F.C. Effects of water deficit on flower opening in coffee (Coffea arabica L.). Tree Physiology, Victoria, v. 10, p.127-139, 1992.

DEAN, L.A. Relationships between rainfall and coffee yields in the Kona district, Hawai. Journal of Agriculture Research, Washington D.C., v. 59, p. 217-222, 1939.

DRINNAN, J.E.; MENZEL, C.M. Synchronization of anthesis and enhancement of vegetative growth in coffee (Coffea arabica L.) following water stress during floral initiation. Journal of Horticultural Science, London, v. 69, p. 841-849, 1994.

DRINNAN, J.E. \& MENZEL, C.M. Temperature affects vegetative growth and flowering of coffee (Coffea arabica L.). Journal of Horticultural Science, London, v. 70, p. 25-34, 1995.

EMBRAPA. Sistema Brasileiro de Classificação de Solos. Rio de Janeiro: Embrapa Solos. Brasília, DF: Embrapa Produção da Informação, 1999. 306p.

FAZUOLI, L.C., GALLO, P.B., CERVELLINI, G.J., BARROS, I.; VAN RAIJ, B. Café. In: J.I. FAL, M.B.P. CAMARGO, M.A. PIZZINATO, J.A. BETTI, A. M. MELO, I.C. DE MARIA; A.M.C. FURLANI (Ed.). Instruções agrícolas para as principais culturas. 6.ed. Campinas, SP: Instituto Agronômico, 1998. (Boletim 200)

FRANCO, C.M. Apontamentos de fisiologia do cafeeiro. Campinas: Secretaria da Agricultura, Coordenadoria de Assistência Técnica Integral, Departamento de Orientação Técnica. 1970. 56 p.

GOPAL, N.H. Some physiological factors to be considered for stabilization of Arábica coffee production in South Indian. Indian Coffee, Bangalore, v. 38, p. 218-221, 1974.

GUERRA, A.F.; ROCHA, O.C.; RODRIGUES, G.C.; SANZONOWICZ, C. Manejo do cafeeiro, com uso de estresse hídrico controlado, para uniformização de florada. In: L. Zambolim (Ed.). Boas práticas agrícolas na produção de café. Viçosa, MG: Editora da Universidade Federal de Viçosa. 2007. p.83-115.

KRUG, C.A. O cálculo da peneira média na seleção do cafeeiro. Revista do Instituto do Café, São Paulo, v. 15, p. 123-127, 1940.

MAGALHÃES, A.C.; ANGELOCCI, L.R. Sudden alteration in water balance associated with flower bud opening in coffee plants. Journal of Horticultural Science, London, v. 51, p. 419-423, 1976. 
MES, M.G. Studies on the flowering of Coffea arabica L. II. Breaking the dormancy of coffee buds. Portugaliae Acta Biologica, Lisboa, v. 4: 342-354, 1957.

MOENS, P. Étude ecologique du development genératif et végétatif des burgeons de Coffea canephora Pierre: l'initiation florale. Inst. Nat. Étude Agron. Congo (INEAC). 1962. (Sér. Scientifique, V. 96)

MONACO, L.C. 1960. Efeito das lojas vazias sobre o rendimento do café Mundo Novo. Bragantia, Campinas, v. 19, p. 1-12, 1960.

PRADO, H., TREMOCOLDI, W.A.; MENK, J.R.F. Levantamento pedológico detalhado do Pólo Regional de Desenvolvimento Tecnológico dos Agronegócios da Alta Paulista, Adamantina (SP). Campinas: Instituto Agronômico. 2003. (Boletim Científico 10, Série Pesquisa Apta)

REIS, A. J.; ARRUDA, H.V. Frutificação no cafeeiro. Bragantia, Campinas, v. 15, p. 93-98, 1956.

RENA, A.B., BARROS, R.S.; MAESTRI, M. 2001. Desenvolvimento reprodutivo do cafeeiro. In: L. Zambolim, (Ed.) Tecnologias de produção de café com qualidade. Viçosa, MG: Editora da Universidade Federal de Viçosa. 2001. p.

RUSSO JÚNIOR, M. Dados climáticos auxiliares para planejamento e projeto de sistemas de irrigação. São Paulo: CESP, 1980.

SAKAI, E. Irrigação na cultura do café. Revista Cedro Rural, Franca, v. 2, p. 16-17, 2000.

SAKAI, E., ARRUDA, F.B., SILVA, E.A., GALLO, P.B., CAVICHIOLI, J.C., PAULO, E.M., BRUNINI, O., PIRES, R.C.M. Efeito da irrigação e temperatura na produção e peneira média do café Obatã em duas regiões do Estado de São Paulo In: SIMPÓSIO DE PESQUISA DOS CAFÉS DO BRASIL, 3., 2003. Anais... Brasília, DF: Embrapa Café. p. 125-126.

SCHOLANDER, P.F., HAMMEL, H.T., BRADSTREET, E.D.; HEMMINGSEN, E.A. Sap pressure in vascular plants. Science, Washington DC, v. 148, p. 339-346, 1965.

SCHUCH, U.K., FUCHIGAMI, L.H.; NAGAO, M.A. Flowering, ethylene production, and ion leakage of coffee in response to water strees and giberellic acid. Journal of American Society of Horticultural Science, Washington, v. 117, p.158-163, 1992.

WENT, F.W. Experimental control of plant growth. Chronica Botanica, Waltham. Massachusets. p. 164-168. 1957.

WORMER, T.M. Some physiological problems of coffee cultivation in Kenya. Café, San Jose, v. 6, 1-20, 1965.

WORMER, T.M.; GITUANJA, J. Seasonal patterns of growth and development of Arabica coffee in Kenya. Part II. Flower initiation and differentiation in coffee east of Rift Valley. Kenya Coffee, v. 35, p. 270-277, 1970. 